\title{
Correction to: Inverse Estimation of Cohesive Fracture Properties of Asphalt Mixtures Using an Optimization Approach
}

\author{
B.C. Hill ${ }^{1} \cdot$ O. Giraldo-Londoño ${ }^{2} \cdot$ G.H. Paulino ${ }^{2} \cdot$ W.G. Buttlar ${ }^{3}$
}

Published online: 1 June 2018

(C) Society for Experimental Mechanics 2018

\author{
Correction to: Exp Mech \\ https://doi.org/10.1007/s11340-017-0257-3
}

The following correction should be noted:

On page 642 , in the seventh line of the third paragraph, the phrase "the Poisson's Ratio is taken as $v=0.33$ " should be replaced with "the Poisson's Ratio is taken as $v=0.25$ for the asphalt mastic group and $v=0.16$ for the aggregate group".

The authors regret any confusion that may have been caused by this error.

The online version of the original article can be found at https://oi.org/ 10.1007/s11340-017-0257-3

W. G. Buttlar

buttlarw@missouri.edu

1 Department of Civil and Environmental Engineering, University of Illinois, Urbana, IL 61801, USA

2 School of Civil and Environmental Engineering, Georgia Institute of Technology, Atlanta, GA 30332, USA

3 Department of Civil and Environmental Engineering, University of Missouri, Columbia, MO 65211, USA 